\title{
Personalisation in MOOCs: A Critical Literature Review
}

\author{
Ayse Saliha Sunar ${ }^{1}$, Nor Aniza Abdullah ${ }^{2}, \mathrm{Su}_{\text {White }^{1}}$ and Hugh Davis ${ }^{1}$ \\ ${ }^{1}$ Electronics and Computer Science, University of Southampton, SO17 1BJ, Southampton, UK \\ \{assla12, saw, hcd\} @ecs.soton.ac.uk \\ ${ }^{2}$ System and Technology, University of Malaya, 50603, Kuala Lumpur, MALAYSIA \\ noraniza@um.edu.my
}

\begin{abstract}
The advent and rise of Massive Open Online Courses (MOOCs) have brought many issues to the area of educational technology. Researchers in the field have been addressing these issues such as pedagogical quality of MOOCs, high attrition rates, and sustainability of MOOCs. However, MOOCs personalisation has not been subject of the wide discussions around MOOCs. This paper presents a critical literature survey and analysis of the available literature on personalisation in MOOCs to identify the needs, the current states and efforts to personalise learning in MOOCs. The findings illustrate that there is a growing attention to personalisation to improve learners' individual learning experiences in MOOCs. In order to implement personalised services, personalised learning path, personalised assessment and feedback, personalised forum thread and recommendation service for related learning materials or learning tasks are commonly applied.
\end{abstract}

Keywords. Personalisation, MOOCs, Literature Survey, Adaptive MOOCs, Learning Analytics, MOOCs personalisation

\section{Introduction}

Massive Open Online Courses (MOOCs) are an emerging area in technologyenhanced learning [1]. Even the first MOOCs course, Connectivism and Connective Knowledge 08 (CCK08), has attracted thousands of learners. It should be noted here, this online course was not announced as a "massive open online course", the term "massive open online course" was first introduced in 2008 by Dave Cormier to describe George Siemens and Stephen Downes' CCK08 online course [2]. The first MOOCs course was based on connectivism theory that addresses issues about connecting people and resources to construct knowledge. It emphasises the importance of providing social platforms to learners to support their interactions with the course content, rather than just transmitting knowledge to them [3]. This kind of MOOCs is later known as cMOOCs.

In 2011, Sebastian Thrun designed a MOOCs course on Artificial Intelligence at Stanford University. Pedagogically, this MOOC was different from the first MOOC. It is more teacher-centric in which learning goals and learning plans were predefined 
for potential learners. This kind of MOOCs is named as xMOOCs, and it is based on the behaviourist learning theory [4].

Even though MOOCs are relatively a new trend in technology-enhanced learning, concerns on teaching and learning with MOOCs are still the same with those on online education [5] [6], for instance, how can MOOCs be pedagogically efficient to address different needs of its learners? Research attempts to address this issue are discussed further in Section 3. One proposed study is to provide MOOCs personalisation through educational data mining in order to improve learning experience in MOOCs. In this paper, the state of the art of personalisation in MOOCs based on a study on the related literatures is presented. The methodology is presented in Section 2. Analysis and findings are reported in Section 3 in order to identify the aspects of MOOCs' personalisation that are commonly addressed by researchers and those that are still not sufficiently look into. The existing personalisation approaches and report of the critical reviews on them are further investigated in the sub sections of Section 3. Based on the findings, suggestions on ways to improve the delivery of personalised learning in MOOCs are provided in Section 4. Section 5 concludes the study and presents suggestions for future work.

\section{Methodology}

In this work, we expanded our survey has been done in [7]. Available literature has been searched on several academic databases between 2011 and July 2015 with the keywords "MOOCs personalisation" and "adaptive MOOCs". Those digital academic databases are Google Scholar (GS), The British Journal of Educational Technology (BJET), American Journal of Distance Education (AJDE), Journal of Online Learning and Technology (JLOT), ISI Web of Knowledge (WoK) and IEEEXplore. The reason of starting with 2011 is that 2011 is the year in which both xMOOCs and cMOOCs have been discussed [4] and MOOCs have become rapidly and widely used in online learning as reported in [8]. While analysing literature, grey literature such as technical report and white papers are analysed along with peer-reviewed articles.

Table 1 and 2 illustrate the number of papers that have been retrieved, along with the number of relevant papers to the personalisation of MOOCs over the years based on the searched keywords "MOOCs personalisation" and "adaptive MOOCs", respectively. While the year 2012 is called and referred many times as "the year of the MOOC", personalisation of MOOCs has been on the rise since 2013.

1 http://www.nytimes.com/2012/11/04/education/edlife/massive-open-online-courses-aremultiplying-at-a-rapid-pace.html 
Table 1. Search results for the keyword "MOOCs personalisation"

\begin{tabular}{|l|c|c|c|c|c|c|c|c|c|c|}
\hline & \multicolumn{2}{|c|}{2011} & \multicolumn{2}{c|}{2012} & \multicolumn{2}{c|}{2013} & \multicolumn{2}{c|}{2014} & \multicolumn{2}{c|}{2015} \\
\hline & $\mathrm{S}$ & $\mathrm{R}$ & $\mathrm{S}$ & $\mathrm{R}$ & $\mathrm{S}$ & $\mathrm{R}$ & $\mathrm{S}$ & $\mathrm{R}$ & $\mathrm{S}$ & $\mathrm{R}$ \\
\hline GS & 17 & 0 & 29 & 1 & 313 & 11 & 427 & 14 & 336 & 16 \\
\hline BJET & 0 & 0 & 0 & 0 & 0 & 0 & 1 & 0 & 0 & 0 \\
\hline AJDE & 0 & 0 & 0 & 0 & 0 & 0 & 4 & 0 & 0 & 0 \\
\hline JOLT & 0 & 0 & 0 & 0 & 0 & 0 & 0 & 0 & 0 & 0 \\
\hline WoK & 0 & 0 & 0 & 0 & 4 & 1 & 0 & 0 & 0 & 0 \\
\hline IEEEXplorer & 0 & 0 & 0 & 0 & 0 & 0 & 0 & 0 & 0 & 0 \\
\hline
\end{tabular}

Table 2. Search results for the keyword "adaptive MOOCs"

\begin{tabular}{|c|c|c|c|c|c|c|c|c|c|c|}
\hline & \multicolumn{2}{|c|}{2011} & \multicolumn{2}{|c|}{2012} & \multicolumn{2}{|c|}{2013} & \multicolumn{2}{|c|}{2014} & \multicolumn{2}{|c|}{2015} \\
\hline & $\mathrm{S}$ & $\mathrm{R}$ & $\mathrm{S}$ & $\mathrm{R}$ & $\mathrm{S}$ & $\mathrm{R}$ & $\mathrm{S}$ & $\mathrm{R}$ & $\mathrm{S}$ & $\mathrm{R}$ \\
\hline GS & 19 & 0 & 72 & $1^{*}$ & 422 & $18^{\pi}$ & 623 & $17^{\pi}$ & 453 & $18^{\mathscr{B}}$ \\
\hline BJET & 0 & 0 & 0 & 0 & 3 & 0 & 1 & 0 & 3 & 1 \\
\hline AJDE & 0 & 0 & 0 & 0 & 0 & 0 & 2 & 0 & 0 & 0 \\
\hline JOLT & 0 & 0 & 0 & 0 & 0 & 0 & 0 & 0 & 0 & 0 \\
\hline WoK & 0 & 0 & 0 & 0 & 3 & $1^{*}$ & 4 & 0 & 0 & 0 \\
\hline IEEEXplorer & 0 & 0 & 0 & 0 & 1 & $1^{*}$ & 5 & $3^{\S}$ & 1 & 1 \\
\hline $\begin{array}{ll}* & 1 \text { same resu } \\
\S & 2 \text { results of } \\
\uparrow & 8 \text { results of } \\
\text { H } & 9 \text { results of } \\
\end{array}$ & $\begin{array}{l}\text { with } \\
\text { em a } \\
\text { em a } \\
\text { em a }\end{array}$ & $\begin{array}{l}\text { e otl } \\
\text { the }\end{array}$ & sea & & her & & & & & \\
\hline
\end{tabular}

The data on the tables is visually interpreted on Figure 1. It clearly illustrates that the amount of attention for personalised learning in MOOCs has drastically increased since 2013. The decrease in 2015 on the figure should not mislead the reader. The results in 2015 show only the first 7 months of 2015 and it is already higher than 2013. It could be higher than the total result in 2014 by the end of the year. In this respect, it cannot be claimed that studies on personalisation in MOOCs are on decrease.

Even though, the number of search results is over 600 papers (see Figure 1), relevant papers are only a few among them (66 papers in total by 2015 July). Papers on studies regarding adaptive online education systems, and other issues related to MOOCs are also retrieved along with papers on mass personalisation in MOOCs with these keywords. However, the relevant papers only indicate studies discussing mass personalisation. 


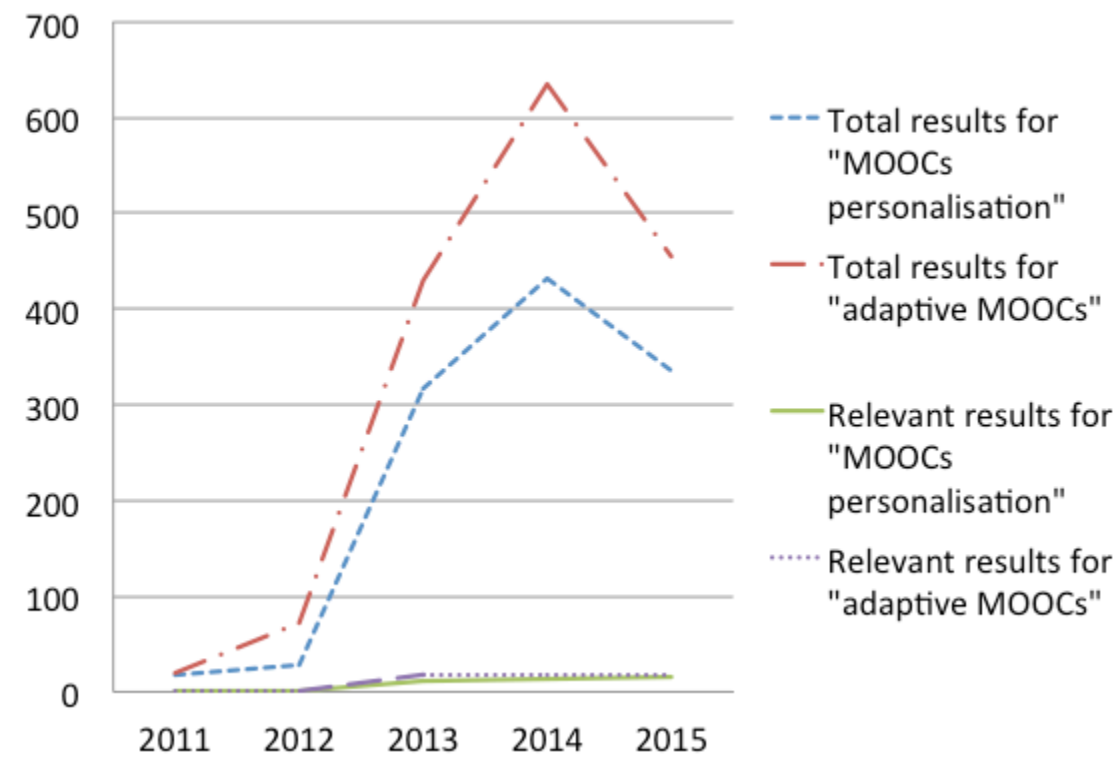

Fig. 1. The total number of papers and relevant papers by the searches for the keywords "MOOCs personalisation" and "adaptive MOOCs"

This work reported in this paper only considers the relevant papers for analysis. The analysis is organised according to the purposes and scoped of the studies, and the personalisation or adaptation techniques used.

\section{Data Analysis}

Once the redundant papers are eliminated from the collection of relevant papers, it is observed that some papers rhetorically indicate needs for personalisation in MOOCs while some others attempt to develop personalisation services in MOOCs. Therefore, the relevant papers are clustered into three categories in this study:

1. NEEDS: Represents the 'Need for personalisation in MOOCs'. This category of research papers indicates the need or opportunity for MOOCs personalisation. They mainly report findings that lead to the need for personalised learning in MOOCs. However, the papers in this category do not propose any project, framework or system for designing or implementing personalisation in MOOCs.

2. PROPOSALS: Represents the 'Plan to implement personalisation in MOOCs'. This category of research papers expresses ideas and proposals for personalisation projects in MOOCs. However, the plans for the intended personalisation systems have not yet been implemented.

3. IMPLEMENTATIONS: Represents the attempts for 'Personalisation Service in MOOCs'. This category of papers expresses partly or fully implemented and ex- 
perimented proposals for personalisation in MOOCs. However, majority of studies in this category are in progression state with no definitive outcome yet.

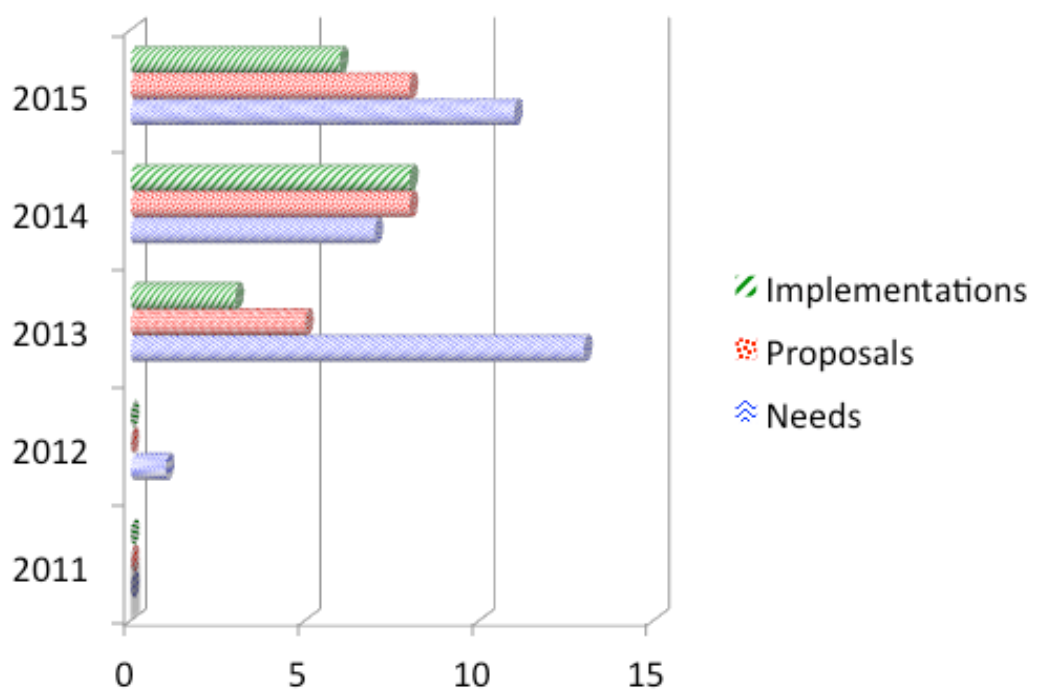

Fig. 2. The number of papers in each category over the years

Figure 2 illustrates the number of papers in each category over the years. The figure denotes that only one paper emphasises the need for personalisation in MOOCs in 2012 while 2013 is the year with the highest number of papers (13) calling for personalisation. In 2013, there are 5 descriptive papers on proposals for personalisation in MOOCs but only 3 papers proposed partly or fully personalised MOOCs functions in MOOCs learning environment. Generally, the number of papers in categories of Proposals and Implementations increases in 2014 and 2015 after the call for adaptive MOOCs in the previous year. The results show that there is a rapid growing of interest towards personalised and adaptive learning in MOOCs. Another case is recognised that some research initially categorised as Proposal is later developed and the outcomes reported as Implementation. For example, Fidalgo-Blanco et al. [9] put forward an adaptive system for MOOCs in 2013 and this article is reported in Proposal. The authors implement their system and reported in [10] in 2015 and this article is reported in Implementation. Even though only 2 studies were found during our investigation, this case shows that research on personalisation in MOOCs has progressed over years. Additionally, it might be assumed therefore that there will be experiments to be fully implemented in the coming years.

\subsection{Category 1: Needs}

The availability of the big data in MOOCs, and tools to perform learning analytics would make it possible for a personalised system to predict learners' learning behav- 
iours and preferences in order to deliver personalised learning and assistance to MOOCs learners [17]. Commentators have shown interest in this since 2013. [11], [12], [13], [14], [15], and [16] indicate that a huge amount of human data can be collected through MOOCs. Shaw also [6] (2012) points out that this pool of human data could be used to create a human model in intelligent tutoring system (ITS) for MOOCs. Similarly, Yates [18] and Knox [19] highlight that data mining and data analytics for prediction could make MOOCs adaptive. Slightly on a different note, Kay et al. [20] predict that educational data mining and learning analytics should be applied for MOOCs' social network analysis to enable personalised learning in MOOCs. Kalz [21] further supports the argument by highlighting that these techniques could make MOOCs a more suitable technology to support lifelong learners. Additionally, Williams et al. [22] point out that collaborative and personalised learning could be supported through MOOCs with those techniques.

The importance of offering personalised learning in MOOCs is further expressed by the following researchers. For instance, Amo [23] believes that MOOCs should offer student-centred learning for effective and quality education in order to meet each individual learner's learning expectations in MOOCs. However, she emphasises that current pedagogy and design of MOOCs is not enough to improve students' outcomes. As there are many exciting and available pedagogies in technology enhanced learning such as peer assistance and assessments, social networking, and gamification, the author suggests for the incorporation of these pedagogies into MOOCs. This can be accomplished through the use of learning analytics and continuous monitoring of students' interactions so that automated assessment with instant feedback can be personalised to every student to improve quality learning in MOOCs. Yousef et al. [24] also consider using peer-assessments to deal with poor assessment system in existing MOOCs in cooperation with blended MOOCs.

Sanna and Anne-Maria [25] also discuss MOOCs pedagogy and personalising learning process to improve individual study plans in a collaborative learning community in MOOCs. Huggings and Smith [26] focus on the same approach to improve higher education by integrating MOOCs into formal higher education.

McLoughlin [27] and Knox et al. [28] address the current inefficiency of learners' feedbacks in MOOCs. They point out that MOOCs environment is convenient for offering personalised contents and feedbacks to learners based on their learning goals. This is because MOOCs provide learning flexibility and sense of independence between learners and teachers that are important when implementing personalisation in technology-enhanced learning. Ling [29] also similarly expresses that personalised and linked learning resources could be helpful for providing feedbacks and resource recommendation in order to overcome static design of MOOCs.

Additionally, Kalz and Specht [30] point out that the current MOOCs design does not consider the diversity of its learners. The authors suggest that building sub groups that share similar attitudes and interests could be a solution. The authors further indicate that the heterogeneity problem in MOOCs community is akin to the problem of learning network. The authors describe learning network as a connection of humans, actors, agents, institutions and learning resources organised for a learning program/course. To deal with diversity in learning networks, several services for learner 
support in learning networks should be utilised, such as placement support service (navigation support), a recommender service, and knowledge matchmaking service. By using these intelligent personalisation techniques, different needs and interests among diverse learners' community in MOOCs can be addressed. To further support the importance of addressing diversity among learners, Cavanaugh [31] whose work focuses on MOOCs assessments for credits for the post secondary education, states that personalised learning pathways for learners could help them build their capabilities to obtain credits.

Kizilcec et al. [32] are concerned with low completion rate in MOOCs. Therefore, they have conducted a study to examine patterns of learners' engagement and disengagement with the MOOCs course, and consecutively they have suggested for MOOCs to offer adaptive content or assistance to learners according to their needs. Their suggestion is further supported by Martin et al. [33] who believe that learning in MOOCs can be encouraged by providing predefined personal paths and super badges that indicate the competence level of each individual learner.

On the other hand, Aoki [34] and Stine [35] focus on business model for MOOCs. While Stine [35] indicates mass personalisation can have a positive business impact to MOOCs, Aoki [34] points out that MOOCs is representing a new business model. Aoki [34] states that content providers for lectures, assessments/accreditation and tutorial supports will eventually be separately established and organised. The author presumes that the learners' data will be shared among separate organisations to enable personalisation in MOOCs.

Despite the apparent needs for personalised learning in MOOCs, Kay et al. [20], Buffat et al. [36] and Daniel et al. [37] point out that the existing MOOCs are not even half way through in implementing personalisation. Nevertheless, without personalisation, learners may reduce their participations and eventually drop out from a MOOC, which is one of the biggest concerns of MOOCs [38]. Noteworthy that even though, there is nonexistence of personalisation practice on the existing MOOCs platforms, Hollands and Tirthali [6] point out that MOOCs still present the term POOC "Personalised Open Online Course" into their full report. It is also stated that the success of MOOCs will depend on how much the learning process is personalised.

\subsection{Category 2: Proposal}

The literature that is considered under this category mainly involves project launches which are funded for the aim of personalising online education for masses, projects' proposals for implementing personalisation services in the existing non-personalised MOOCs, and conceptual research frameworks.

Most of the research works are driven by concerns over the inefficiency of MOOCs design, delivery, and assessments. For instance, Daradoumis et al. [39] and Bassi et al. [40] voice their concerns in several different research papers. According to the authors, as most of MOOCs courses are not learner-centric, and they provide same content for all learners, the effectiveness of the tutoring is generally poor, feedbacks are insufficient and peer-based evaluation is usually unprofessional. To address these deficiencies, the authors propose an agent-based framework for MOOCs. Agents 
collect data and analyse them according to several perspectives including educational goal, pedagogical preferences, time management and so forth. The analysed data is used by other agents for content customisation, tutoring feedback, system-learner alert as well as assessing and monitoring learners' learning progress in MOOCs. The authors indicate that intelligent agents could also be used for reducing fraud and cheating during online tests.

In a most recent research, Paquette et al. [41] enrich an agent-based framework with a competency-based model to generate recommendations of learning scenarios. In order to give learners recommendations, learners are grouped as novice, intermediate, and advanced in this research.

Yee-King and d'Inverno [42] is another research using agent-based model to personalise MOOC education recently in 2015. In this research, agents store the information about learners such as goals of person and current state of skills. Agents also identify learners' current state and data/content provided to find an optimal learning plan and possible human connections that might be helpful.

Broun et al. [43] put forward a personalisation component which will be integrated to the existing EMMA platform ${ }^{2}$. EMMA platform is a MOOC platform delivering courses in different languages from different European Universities; therefore, learners may be overwhelmed with huge number of courses and language choices. Through this personalisation component, EMMA aims to provide personalised feedback and individualised learning paths to support learners to achieve their learning goals.

Similarly, Wilkowski et al. [44] have conducted an analysis on learners' goals and their achievements on the tested skills and activities by executing "Mapping with Google" course in MOOCs. Each learner was asked to complete a questionnaire about their learning goals to join the course and their previous experiences with the Google map. The authors then compared learners' learning goals with their behaviours in the course (i.e. watched videos, completed activities), and found out that their behaviours were very much determined by their goal. Therefore, the authors conclude that the course delivery could be personalised based on learners' goals. Their proposed system could be adapted to learner's requirements in two ways. First is to ask for learners' goals prior to delivering personalised learning pathway to each of them. Secondly, to have learners select the course elements such as some video lectures and assessments from a list for a customised course.

Leony et al. [45] focus on identifying learners' emotions in order to serve learner with personalised content. The authors propose four models for detection of frustration, confusion, boredom and happiness by using learners' activities such as how many quiz they take, how much time they spent on it, how many badget they have and so on. The authors plan to test model in a MOOC for improving learners' engagement in MOOCs.

Pham and Wang [46] consider ITS for optimising benefit from video lectures of MOOCs on a mobile device. In order to identify learners' mind wandering and heart rate, the system uses on-lens finger gestures. Even though it has not evaluated on a

2 http://platform.europeanmoocs.eu 
MOOC platform, it could be beneficial for to help instructors understand learners' progress.

De Maio et al. [47] also believe that learners' engagement with the video lecture materials in MOOCs as passive. To improve learners' engagement with MOOCs, the authors propose a methodology to support learners to navigate the fragments of one or more videos lectures so that learners could connect their goals and prior knowledge with the key concept of the lectures. The authors use taxonomy building for constructing a knowledge model for the concepts of lectures. The main idea is to enable interlinking between different MOOCs courses and navigate learners to related ones. However, this part of the research has not been conducted.

Fasihuddin et al. [48] propose an approach for personalised learning experience in MOOCs based on learners' learning styles. The authors define the kind of material that should be included in the lecture for a particular learning style. For example, while visual learning objects should be accessible for visual learners, such need is not a necessity for verbal learners. However, this is an ongoing research and a prototype is still not yet completed.

Elkherj and Freund [49] have developed an adaptive hint system for the undergraduate online course "Introduction to probability and Statistics" on the Webwork, which is a platform for managing homework assignments in mathematics. This course was attended by 176 students and hints were written by the tutor each time learners made a mistake or failed a test. The authors express that the need for manual labour for analysing learners' failure and writing helpful hints makes the system inconvenient for MOOCs. Therefore, they propose some possible approaches that could address this problem. The first is for students to hints to their peers. Secondly, create hint libraries. Finally, use machine-learning techniques to map students' mistakes with hints and consecutively send the most relevant hint to them.

Brouns et al. [50] propose ECO sMOOC for the EU-funded project called Elearning, Communication and Open-data: Massive Mobile, Ubiquitous and Open Learning (ECO). sMOOC refers to being a social-based MOOCs which is accessible from different types of social media and mobile devices. Learning is executed devices through content contextualisation based on learners' interactions and participations in the course using mobile and gamification approaches. The ECO sMOOC environment is described as learner-centric approach, which is adaptable to learners' intention. However, the project is in the very early stage, and any real experience with it has not yet available.

Bain et al. [51] suggest AMOOC (Accessible Open Online Course) movement to make MOOC courses more accessible for learners with disabilities. The paper focuses on delivering course content in appropriate forms for disable learners. They also mention that the system will be conducted using Adaptive Mobile Online Learning (AMOL) for adapting coursework to each learner's learning style. Similarly, SanchezGordon and Lujan-Mora [52] also focus on enabling education for disabled learners. They have proposed an adaptive content presentation in MOOCs based on the disability that learners have such as blind, low vision, deaf, dyslexia.

Collet [53] proposes POEM (Personalised Open Education for the Masses) platform project for designing personalised learning management system (LMS) for mas- 
sive learning. The author believes that personalisation of massive education is only possible with intelligent ICT (Information and Computing Technology) platforms. In POEM, visual and dynamic Knowledge Maps of domains for each course are constructed to provide different possible learning paths to learners. POEM will also provide inter-tutorship and automatic assessments. Apart from that, the system will ask learners to post new questions or new contents to the platform.

Bansal [54] and Birari [55] have utilised the concept of ITS for personalising learning experiences with MOOCs from different perspectives. Bansal [54] focuses on providing recommendations for learners to do additional learning activities to improve their lack of knowledge on a particular topic. In order to model learners' knowledge, the author uses the fuzzy cognitive map. On the other hand, Birari [55] models learners' cognitive state by Bayesian network so that adaptive testing and adaptive guidance can be delivered to learners.

Slightly on a different note, Fidalgo-Blanco et al. [56] has identified three weaknesses in MOOCs: high dropout rate, lack of cooperative activities among learners, and poor continuity of learning communities when a MOOCs course ends. According to the authors' definition, learning community includes activities, resources, and similar groups. To improve learning experiences in MOOCs, the authors have outlined the components of learning community that should be personalised based on learners' learning goals, previous knowledge, etc. These personalisation inputs are captured and diagnosed through initial assessments.

Similarly, Zhuhadar and Butterfield [57] point out that providing a singular curriculum to a diverse MOOCs community has caused low completion rates in MOOCs. To address this problem, the authors propose Personalised Open Collaborative Courses (POCCs) which tracks learners' attitude during the course and delivers the personalised content based on learners' activities and their prior-knowledge. In order to achieve this goal, the authors examine sub communities in MOOCs to design a personalised social recommender system.

\subsection{Category 3: Implementation}

Research works reported in this category provide a more concrete evidence of approaches towards implementing personalisation in MOOCs. This category considers either partly or fully implemented personalised systems that may have performed some kind of testing on either system performance or student performance. Noteworthy that majority of the systems have not yet completed their final evaluations, and the projects are still ongoing.

An algorithm of an adaptive study planner for MOOCs learners, targeted to novice learners in MOOCs is presented by Alario-Hoyos et al. [58] and Gutiérrez-Rojas et al. [59]. The adaptive planner creates a personalised study schedule for each learner based on their priority of the course, available time slot and the course requirements. Alario-Hoyos et al. present further improvement and implementation of their research in [60]. Likewise, Cordier et al. [61] develop a tracing system to help learners control their learning activities on different learning platforms. 
Burgos and Corbí [62] present a rule-based technology-enhanced learning recommendation model in order to improve users' performance in MOOCs and other Open Educational Resources (OERs). The model tracks learners' performances and their interactions with the lectures. It consecutively map the related data according to the tutor's rules for recommendation such as minimum number of required activity in a lecture and minimum score on a given test. Based on the results of rules mapping, a recommendation is made. If a learner satisfies the tutor's rule to be successful, then the learner gets positive comment such as "Well done!" and gets recommendation for the subsequent tasks. Otherwise, the system gives alert feedback to the learner to request support from the online tutor and peers, and locks any further activities.

Ketamo [63] utilises ITS technologies for providing recommendations to support learners' cognitive progress and motivation in MOOCs. The content that will be provided to learners is defined as semantic network. This approach requires a learner to complete and succeed relevant test on a learning concept prior to recommending the next related learning concepts. According to the preliminary evaluation results, learners' performances were improved when using the recommendation service. However, a considerable portion of learners was still not motivated to learn, and eventually dropped the course.

Cook et al. [7] propose a user model for MOOCs. The proposed user model tracks learners' activities such as when a learner loads a document or when a learner checks a problem. The system models learners' current situation based on defined learning objectives and intended learning outcomes along with each learner's activity on the MOOC.

Shatnawi et al. [65], [66] propose system architecture for providing personalised feedback to learners in MOOCs by using text-mining technique. Since the course creators are not able to provide timely feedback due to massive number of learners, the authors propose a method for providing_automatic content related feedback by using domain ontology, machine learning, and natural language processing. When a learner writes a post, the system will determine its type, whether it is a question, a comment, or a feedback, and organised it into a suitable domain under the related topic in a repository. If a learner posts a question, the system will automatically search the repository and returns semantically relevant information or personalised feedback to the learner.

Sonwalker [67] proposes an adaptive MOOC that offers adapted learning contents based on learning styles with the concern of pedagogical effectiveness of MOOCs. The author proposes the learning cube that illustrates organisation of learning objects developed in text, graphics, audio, video, animations, and simulations according to different learning styles. In this study, learners' learning style is diagnosed via a diagnostic test as suggested by Fidalgo-Blanco et al. [56]. The performance test result is promising. Sonwalker further improve the adaptive system with the aid of cloud computing reported in [68].

Fidalgo-Blanco et al. [69] have improved their research, which is discussed in Section 3.2 [56], and tested with a pilot. They also aim to provide learners with adaptive content presentation based on their profile and preferences likewise [68]. Therefore, the authors build a technological framework 1) to adapt learning activities (provided 
by $\mathrm{x}$ MOOCs and cMOOCs) to learners' profile and preferences and 2) to enable knowledge management, and 3) to use learning analytics to monitor learners' cooperative works.

Yang et al. [70] design a personalised support on MOOCs discussion forums for helping learners to reach the topics in which they are interested. The authors use both collaborative and content filtering techniques to capture the most relevant forum threads. Their system performance test results show that the system performance of the proposed personalisation model is satisfactory, however, learners' satisfaction test has not yet examined.

Agrawal et al. [71] also consider the large amount of post on discussion forums in MOOCs. The system is proposed in the paper first identifies confusion that is stated in a post on discussion forum and recommends a related education video clip to the object of confusion. So that, if a learner's post is overlooked by an instructor in a pile of posts on discussion forum, the learner will receive intelligent and adaptive help to solve their confusion.

Some researchers modify existing personalised technology-enhanced learning systems for MOOCs courses. For example Miranda et al. [72]'s work aims to provide a pedagogy-based guide for items assessment based on the ontological relations between learning subjects in the lectures which are defined by the course creator. According to a learner's assessment's score, a personalised learning pathway is constructed for the learner. Similarly, Henning et al. [73] also adapt an existing technology-enhanced learning system into MOOCs. The system supports learners through personalised navigation based on their learning performances and the association between learning subjects.

\section{Discussion}

Result from the analysis of the needs related literature shows that the pedagogical design of MOOCs is insufficient, therefore, educational data mining should be applied to provide personalised services such as personalised learning pathways, personalised assessments, adaptive feedbacks, and recommender services. To address the needs for personalisation in MOOCs, research in category Proposals and category Implementations have proposed several outlines, frameworks, and projects' proposals, as well as prototypes for implementing personalisation and adaptation in MOOCs.

For instance, Kalz and Specht [30], Kizilcec et al. [32], and Ye et al. [17] from category Needs suggest to cluster MOOCs's learners for personalisation. The suggestion was implemented by Fidalgo-Blanco et al. [56], Fasihuddin [48], Sonwalker [67], and Paquette [41] in which they applied a diagnostic test at the beginning of the course to understand which group (i.e. learning style) a learner belongs to. However, this method is based on learners' participations in the diagnostic test, and majority of learners are not interested in doing tests. Realising this problem, Zhuhadar and Butterfield [57] have suggested using some social networking analysis (SNA) techniques to diagnose learners and automatically cluster them according to the most suited sub community in MOOCs based on their activities. Even though this method does not need learner's self-statement, a learner is required to participate in the course's lec- 
tures and activities until the system can gather sufficient information about the learner in order to determine a suitable cluster for the learner.

Another example is by the work of Shaw [6] who believes that the application of ITS technique can actualise mass personalisation in MOOCs. The belief was translated by Pham and Wang [46], Bansal [54], Bariri [55], and Ketamo [63] who implemented ITS techniques in MOOCs for personalising contents, learning pathways, and providing recommendations. Additionally, Cok et al. [64] also offers a user model for modeling learners' current state.

Note that even though Yang et al. [70] and Brouns et al. [50] did consider the social feature of MOOCs, for example they personalise online forum threads to learners based on their forum activities and peers connections, they did not build a personalised learning network in MOOCs or social network analysis for improving learning networks as suggested by Kalz and Specht [30] and Kay et al. [20]. Therefore, continuity problem of learning communities identified by Fidalgo-Blanco et al. [57] remains unsolved.

\section{Conclusion}

In conclusion, this literature survey has demonstrated that there is a growing trend of researchers embarking in the possibility of implementing personalisation and adaptation in MOOCs in order to improve users' engagements, hence reduce MOOCs' dropout rate problem. 66 papers are identified as relevant to personalisation of MOOCs and deeply examined. The trend is mainly motivated by the fact that MOOCs learning has the potential to spark demands for personalised learning due to its massive and geographically dispersed learners with diverse background. In addition to that, MOOCs environment does provide the basic requirements for personalised learning such as the availability of huge learners' data, flexible learning, and learner-teacher independence. Our categorisation of the literature identified three distinct types of papers.

1. These concerned with the need or motivation for personalisation in MOOCs.

2. Outlines of plans or proposals for implementing personalisation in MOOCS.

3. Accounts and evaluations of the implementation of personalisation services in MOOC.

We found that data mining techniques are often used to exploit huge learners' data in MOOCs, and majority of the studies are concerned on the pedagogical design issues. Therefore, many researchers have proposed solutions based on personalisation and adaptation techniques such as personalised learning pathways and personalised feedback. However, there is not yet any tangible research that focuses on building personalised learning networks even though the need has been identified by Kalz and Specht [30], Kay et al. [20] and Fidalgo-Blanco et al. [56]. It is expected that this issue will gain more attention in the nearest future. 


\section{References}

1. Jona, K., and Naidu, S.: MOOCs: Emerging Research. Distance Education, 35(2), 141-144 (2014)

2. McAuley, A., Stewart, B., Siemens, G., \& Cormier, D.: The MOOC model for digital practice. University of Prince Edward Island, 33 (2010)

3. Siemens, G.: Connectivism: A learning theory for the digital age. International journal of instructional technology and distance learning, 2(1), 3-10 (2005)

4. Daniel, J.: Making sense of MOOCs: Musing in a maze of myth, paradox and possibility. Journal of Interactive Media in Education, 3 (2012)

5. Hollands, F. M., Tirthali, D.: MOOCs: Expectations and reality. Full report. Center for Benefit-Cost Studies of Education, Teachers College Columbia University (2014) http://cbcse.org/wordpress/wptent/uploads/2014/05/MOOCs_Expectations_and_Reality.pdf

con-

6. Shaw, C.: Intelligent Tutors and Personalized Education. (2012) http://isites.harvard.edu/fs/docs/icb.topic1283433.files/Shaw_12_rs.pdf

7. Sunar, A.S., Abdullah, N.A., White, S., Hugh, C.D.: Personalisation of MOOCs: The state of the art. In: 7th International Conference on Computer Supported Education, CSEDU 2015. Vol. 1., pp. 88-97 (2015)

8. Liyanagunawardena, T. R., Adams, A. A., Williams, S. A.: MOOCs: A systematic study of the published literature 2008-2012. The International Review of Research in Open and Distance Learning, 14(3), 202-227 (2013)

9. Fidalgo-Blanco, Á., García-Peñalvo, F. J., Sein-Echaluce, M.: A methodology proposal for developing adaptive cMOOC. In: First International Conference on Technological Ecosystem for Enhancing Multiculturality, pp. 553-558, ACM (2013)

10. Fidalgo-Blanco, Á., Sein-Echaluce, M. L., García-Peñalvo, F. J.: Methodological Approach and Technological Framework to break the current limitations of MOOC model. Journal of Universal Computer Science, 21, 712-734 (2015)

11. Bartlett-Bragg, A.: The new normal: Emerging trends in 2015. Training \& Development, 42(2), 17 (2015)

12. Fasimpaur, K.: Massive and Open. Learning and Leading with Technology March/April 2013, 12-17 (2013)

13. Freeman, M., Hancock, P.: Milking MOOCs: Towards the right blend in accounting education. Academic Leadership Series, 4, 86-100 (2013)

14. Godwin-Jones, R.: Emerging Technologies Global Reach and Local Practice: the Promise of MOOCs. Announcements \& Call for Papers, 5 (2014)

15. Harman, K., Koohang, A.: MOOC 2050: A Futuristic Tour. Issues in Information Systems, 14 (2), 346-352 (2013)

16. O'Donnell, E., Lawless, S., Sharp, M., Wade, V.: A review of personalised e-learning: Towards supporting learner diversity, International Journal of Distance Education Technologies, $22-47$ (2015)

17. Ye, C., Kinnebrew, J. S., Biswas, G., Evans, B. J., Fisher, D. H., Narasimham, G., Brady, K. A.: Behavior Prediction in MOOCs using Higher Granularity Temporal Information. In: Second (2015) ACM Conference on Learning@ Scale, pp. 335-338, ACM (2015)

18. Yates, R.: Educational Technologies to Support New Directions in Teaching Practice. International Journal of Information \& Education Technology, 3(6) (2013)

19. Knox, J.: From MOOCs to Learning Analytics: Scratching the surface of the 'visual'. eLearn, 2014(11), 3 (2014) 
20. Kay, J., Reimann, P., Diebold, E., Kummerfeld, B.: MOOCs: So Many Learners, So Much Potential... IEEE Intelligent Systems, 28(3), 70-77 (2013)

21. Kalz, M. (in press): Lifelong Learning and its support with new technologies. In Smelser, N. J. and Baltes P. B. (Eds.). International Encyclopaedia of the Social and Behavioral Sciences. Pergamon: Oxford. (2014)

22. Williams, J. J., Kim, J., Keegan, B. C.: Supporting Instructors in Collaborating with Researchers using MOOClets. Available at SSRN 2580666 (2015)

23. Amo, D.: MOOCs: experimental approaches for quality in pedagogical and design fundamentals. In: First International Conference on Technological Ecosystem for Enhancing Multiculturality, pp. 219-223, ACM. (2013)

24. Yousef, A. M. F., Wahid, U., Chatti, M. A., Schroeder, U., Wosnitza, M.: The Effect of Peer Assessment Rubrics on Learners' Satisfaction and Performance Within a Blended MOOC Environment. In: CSEDU 2015 conference, Vol. 2, pp. 148-159 (2015)

25. Sanna, R., Anne-Maria, K.: WANTED: MOOC PEDAGOGY. EduLearn15 (2015)

26. Huggins, S., Smith, P.: Using an 'open approach' to create a new, innovative higher education model. Open Praxis, 7(2), 153-159 (2015)

27. McLoughlin, C. E.: The pedagogy of personalised learning: exemplars, MOOCS and related learning theories. In: Educational Multimedia, Hypermedia and Telecommunications, Vol. 2013, No. 1, pp. 266-270 (2013)

28. Knox, J., Ross, J., Sinclair, C., Macleod, H., Bayne, S.: MOOC Feedback: Pleasing All the People?. Invasion of the MOOCs, 98 (2014)

29. Ling, J.: Research of Construction Plan for Computer Basics Personalized Intelligent MOOCs Resources. In: 3rd International Conference on Management, Education, Information and Control (MEICI 2015), pp. 1613-1616 (2015)

30. Kalz, M., Specht, M.: If MOOCs are the answer-did we ask the right questions. Implications for the design of large-scale open online courses. Maastricht School of Management in its series Working Papers, 2013/25 (2013)

31. Cavanaugh, J.: The Coming Personalization of Postsecondary Education Competencies. CAEL 2013 Forum \& News: Competency-Based Education, 2-5 (2013)

32. Kizilcec, R. F., Piech, C., Schneider, E.: Deconstructing Disengagement: Analyzing Learner Subpopulations In Massive Open Online Courses. In: third international conference on learning analytics and knowledge, pp.170-179. ACM (2013)

33. Martin, S., Peire, J., Castro, M.: Proyecto WePrendo. Retrieved from http://www.ieec.uned.es/Investigacion/archivos/informe\%20WEPRENDO_DIEEC.pdf (2013)

34. Aoki, K.: Paradoxes between Personalisation and Massification: The Future of Education, Conference Proceedings 2013. $3^{\text {rd }}$ Edition. (2013)

35. Stine, J. K.: MOOCs and executive education. In Presented at the Directors Conference. http://uniconexed.org/2013/research/UNICON-Stine-Research-06-2013-final.pdf (2013)

36. Buffat, M., Mille, A., Picasso, M.: Feedbacks on MOOCS. ESAIM: Proceedings and Surveys, 50, 66-80 (2015)

37. Daniel, J., Cano, E. V., Gisbert, M.: The Future of MOOCs: Adaptive Learning or Business Model?. RUSC. Universities and Knowledge Society Journal, 12(1), 64-73 (2015)

38. Stevanović, N.: Effects Of Motivation On Performance Of Students In MOOC. SINTEZA 2014 Internet and Education, 418-422 (2014)

39. Daradoumis, T., Bassi, R., Xhafa, F., Caballé, S.: A review on massive elearning (MOOC) design, delivery and assessment. In: P2P, Parallel, Grid, Cloud and Internet Computing (3PGCIC), pp. 208-213, (2013), IEEE 
40. Bassi, R., Daradoumis, T., Xhafa, F., Caballé, S., Sula, A.: Software Agents in Large Scale Open Elearning: A Critical Component for the Future of Massive Online Courses (MOOCs). In: Sixth IEEE International Conference on Intelligent Networking and Collaborative Systems, SINCOS, pp. 184-188 (2014)

41. Paquette, G., Mariño, O., Rogozan, D., Léonard, M.: Competency-based personalization for massive online learning. Smart Learning Environments, 2(1), 1-19 (2015)

42. Yee-King, M., d'Inverno, M.: Pedagogical agent models for massive online education. In: First International Workshop on AI and Feedback, AInF 2015, pp. 2-9 (2015)

43. Brouns, F., Tammets, K., Padrón-Nápoles, C. L.: How can the EMMA approach to learning analytics improve employability?. (2014) http://dspace.learningnetworks.org/bitstream/1820/5542/1/submission9_M4WS.pdf

44. Wilkowski, J., Deutsch, A., Russell, D. M.: Student skill and goal achievement in the mapping with google MOOC. In: first ACM conference on Learning@ scale conference, pp. 3-10, ACM (2014)

45. Leony, D., Muñoz-Merino, P. J., Ruipérez-Valiente, J. A., Pardo, A., Kloos, C. D.: Detection and Evaluation of Emotions in Massive Open Online Courses. Journal of Universal Computer Science, 21(5), 638-655 (2015)

46. Pham, P., Wang, J.: AttentiveLearner: Improving Mobile MOOC Learning via Implicit Heart Rate Tracking. Artificial Intelligence in Education, Lecture Notes in Computer Science, 912, 367-376 (2015)

47. De Maio, C., Loia, V., Mangione, G. R., Orciuoli, F.: Automatic Generation of SKOS Taxonomies for Generating Topic-Based User Interfaces in MOOCs. In Open Learning and Teaching in Educational Communities, 398-403, Springer International Publishing (2014)

48. Fasihuddin, H. A., Skinner, G. D., Athauda, R. I.: Personalizing Open Learning Environments through the adaptation to Learning Styles. In: ICITA 2014, $9^{\text {th }}$ International Conference on Information Technology and Applications, Sydney, Australia, July 2014, ISBN: 978-0-9803267-6-5 (2014)

49. Elkherj, M., Freund, Y.: A system for sending the right hint at the right time. In: first ACM conference on Learning@ scale conference,pp. 219-220, ACM (2014)

50. Brouns, F., Mota, J., Morgado, L., Jansen, D., Fano, S., Silva, A. Teixeira, A.: A networked learning framework for effective MOOC design: the ECO project approach. In A. M. Teixeira, \& A. Szücs (Eds.), 8th EDEN Research Workshop, Challenges for Research into Open \& Distance Learning: Doing Things Better: Doing Better Things, 161-171, Budapest, Hungary: EDEN, Oxford, United Kingdom (2014)

51. Bain, K., Chan, B., and Bates, L.: AMOOC: Improving Access to MOOCs using Speech Recognition. (2013) http://liberatedlearning.com/wp-content/uploads/2011/02/AMOOC_Apr_2013.pdf

52. Sánchez Gordón, S., Luján Mora, S.: Adaptive Content Presentation Extension for Open edX: Enhancing MOOCs Accessibility for Users with Disabilities. In: Eight International Conference on Advances in Computer-Human Interactions, pp.181-183 (2015)

53. Collet, P.: POEM (Personalised Open Education for the Masses). (2013) http://blog.educpros.fr/pierredubois/files/2013/07/Financement.pdf

54. Bansal, N.: Adaptive recommendation system for MOOC. Doctoral dissertation, Indian Institute of Technology, Bombay (2013)

55. Birari, N.: Intelligent Tutoring System using Computerised Adaptive testing and interaction logs for MOOCs. Doctoral dissertation, Indian Institute of Technology, Bombay (2014) 
56. Fidalgo-Blanco, Á., García-Peñalvo, F. J., Sein-Echaluce, M.: A methodology proposal for developing adaptive cMOOC. In: First International Conference on Technological Ecosystem for Enhancing Multiculturality, pp. 553-558, ACM (2013)

57. Zhuhadar, L., Butterfield, J.: Analyzing Students Logs in Open Online Courses Using SNA Techniques. In: 20th Americas Conference on Information Systems, AMCIS 2014 (2014)

58. Alario-Hoyos, C., Leony, D., Estévez-Ayres, I., Pérez-Sanagustín, M., Gutiérrez-Rojas, I., Kloos, C. D.: Adaptive planner for facilitating the management of tasks in MOOCs. In: V Congreso Internacional sobre Calidad y Accesibilidad de la Formación Virtual, CAFVIR 2014, Antigua Guatemala, Guatemala, pp. 517-522 (2014)

59. Gutiérrez-Rojas, I., Alario-Hoyos, C., Pérez-Sanagustín, M., Leony, D., Delgado-Kloos, C.: Scaffolding Self-learning in MOOCs. Proceedings of the Second MOOC European Stakeholders Summit, EMOOCs, 43-49 (2014)

60. Alario-Hoyos, C., Estévez-Ayres, I., Sanagustín, M. P., Leony, D., Kloos, C. D.: MyLearningMentor: A Mobile App to Support Learners Participating in MOOCs. Journal of Universal Computer Science, 21(5), 735-753 (2015)

61. Cordier, A., Derbel, F., Mille, A.: Observing a web based learning activity: a knowledge oriented approach. Research report, LIRIS UMR CNRS 5205 (2015)

62. Burgos, D., and Corbí, A.: A recommendation model on personalised learning to improve the user's performance and interaction in MOOCs and OERs. UNESCO Institute for Information Technologies in Education, IITE 2014 International Conference, Oct 14th-15th, 2014,Moscow, Russia (2014)

63. Ketamo, H.: Learning Fingerprint: Adaptive Tutoring for MOOCs. In: World Conference on Educational Multimedia, Hypermedia and Telecommunications, Vol. 2014, No. 1, pp. 2458-2467 (2014)

64. Cook, R., Kay, J., Kummerfeld, B.: MOOClm: User Modelling for MOOCs. In User Modeling, Adaptation and Personalization, 80-91, Springer International Publishing (2015)

65. Shatnawi, S., Gaber, M. M., Cocea, M.: Text stream mining for Massive Open Online Courses: review and perspectives. Systems Science \& Control Engineering: An Open Access Journal, 2(1), 664-676 (2014)

66. Shatnawi, S., Gaber, M. M., Cocea, M.: Automatic content related feedback for MOOCs based on course domain ontology. In Intelligent Data Engineering and Automated Learning-IDEAL 2014, 27-35, Springer International Publishing (2014)

67. Sonwalkar, N.: The First Adaptive MOOC: A Case Study on Pedagogy Framework and Scalable Cloud Architecture-Part I. In MOOCs Forum, Vol. 1, No. P, 22-29 (2013)

68. Sonwalkar, N.: Cloud Based Adaptive Learning Systems. White Paper (2015) http://static1.squarespace.com/static/53eb8591e4b0ba68f27eea55/t/54c65ff2e4b064f7f8ee 9a07/1422286871164/CloudbasedAdaptiveWhitePaper.pdf

69. Fidalgo-Blanco, Á., Sein-Echaluce, M. L., García-Peñalvo, F. J.: Methodological Approach and Technological Framework to break the current limitations of MOOC model. Journal of Universal Computer Science, 21, 712-734 (2015)

70. Yang, D., Piergallini, M., Howley, I., Rose, C.: Forum thread recommendation for massive open online courses. In: 7th International Conference on Educational Data Mining (2014)

71. Agrawal, A., Venkatraman, J., Leonard, S., Paepcke, A.: YouEDU: Addressing Confusion in MOOC Discussion Forums by Recommending Instructional Video Clips. In: Eight International Conference on Educational Data Mining, pp. 297-304 (2015)

72. Miranda, S., Mangione, G. R., Orciuoli, F., Gaeta, M., Loia, V.: Automatic generation of assessment objects and Remedial Works for MOOCs. In Information Technology Based Higher Education and Training (ITHET), 1-8. IEEE (2013) 
73. Henning, P. A., Heberle, F., Streicher, A., Zielinski, A., Swertz, C., Bock, J., Zander, S.: Personalized Web Learning: Merging Open Educational Resources into Adaptive Courses for Higher Education. Personalization Approaches in Learning Environments, 55 (2014) 